Document downloaded from:

http://hdl.handle.net/10251/51593

This paper must be cited as:

Velasco De La Fuente, D.; Trujillo Rodríguez, CL.; Garcerá Sanfeliú, G.; Figueres Amorós, E. (2011). An active Anti-islanding method based on phase-PLL perturbation. IEEE Transactions on Power Electronics. 26(4):1056-1066. doi:10.2089643.

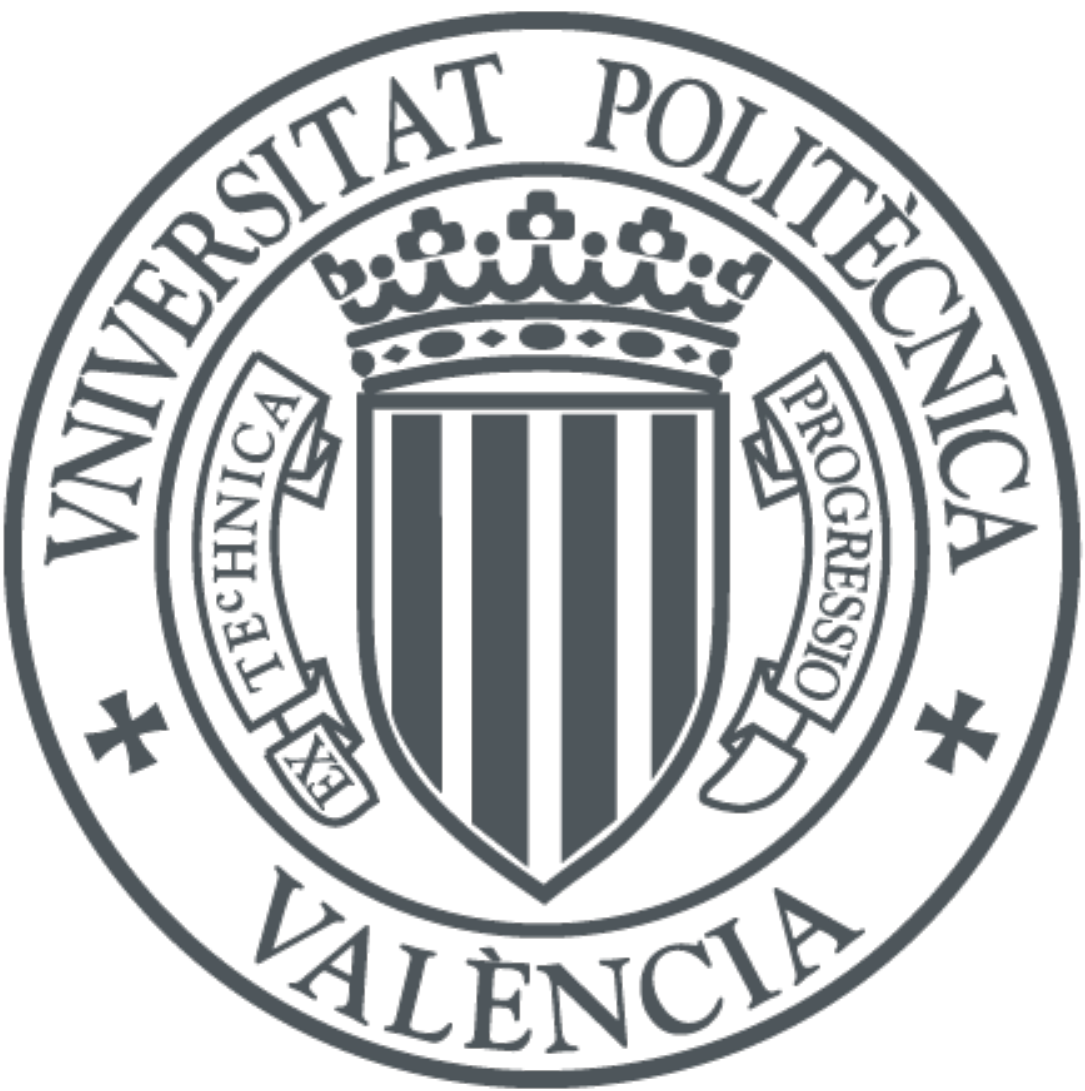

The final publication is available at

http://ieeexplore.ieee.org/xpl/articleDetails.jsp?arnumber=5609214

Copyright Institute of Electrical and Electronics Engineers (IEEE)

Additional Information 


\section{An active Anti-islanding method based on phase-PLL perturbation}

David Velasco ${ }^{1}$, César Trujillo ${ }^{1,2}$, Gabriel Garcerá ${ }^{1}$, Emilio Figueres ${ }^{1}$

1 Grupo de Sistemas Electrónicos Industriales del Departamento de Ingeniería Electrónica, Universidad Politécnica de Valencia. davede@upv.es, ggarcera@eln.upv.es, efiguere@eln.upv.es

2 Departamento de Ingeniería Electrónica, Universidad Distrital Francisco José de Caldas. cltrujillo@udistrital.edu.co

Abstract- This paper presents a new active anti-islanding detection method for distributed power generation systems. This method is based on introducing a disturbance at the inverter output and observing the behaviour of the voltage at the point of common coupling (PCC), which depends on the impedance connected to the PCC in an islanding situation. The islanding detection is based on the Goertzel algorithm.

\section{INTRODUCTION}

In the last years, one of the priorities worldwide is developing alternative sources to produce electric energy, especially from renewable sources, which produce low environmental contamination levels. Those renewable energy sources have an important role in the long-term, and they will give rise to substantial changes in the technologic, environmental and organizational profile of the global energy system [1].

Furthermore, the possibilities to produce energy closely to the consumption centers, and energetic delivery weaknesses in isolated and rural areas, turn the distributed generation (DG) [2] into an interesting and promising technological option.

Accordingly to the expressed above, it is feasible to implement interfaces able to get connected to the grid in order to transfer the energy coming from renewable sources (grid mode), as well as to feed loads when there is a lack of it (island mode). Those interfaces are known as microgrids [3]. A microgrid is able to flexibly import and export energy from and to the grid. It controls the flow of active and reactive power [4].

Moreover, the condition of "Islanding" in a distributed power generation system is an electrical phenomenon which occurs when the energy supplied by the power grid is interrupted and the distributed generators (DGs) continue energizing the loads. Thus, the power grid stops controlling this isolated part of the distribution system, which contains both loads and generation, so that security, restoration of service and reliability of the equipment may be compromised [5].

However, in some microgrids, the inverters which change their control structure depending on the connectiondisconnection status of the microgrid to the main grid [6]. When the main grid is connected, the inverters work injecting a current in phase with the voltage at the PCC. When the microgrid becomes isolated from the grid, the inverters change their control configuration, working as voltage sources and using some droop method [7], [8] to share the power demanded by the local loads. This change in the microinverter control structure is decided by some islanding detection method. 
The main idea to detect an Islanding situation is to supervise the DGs output parameters and/or other system parameters in order to determine whether changes indicating an islanding condition have occurred. Islanding detection techniques can be divided into remote and local ones, whereas the latter techniques are divided into passive and active ones, as shown in Fig. 1 [9].

Before defining the different methods for islanding detection, it is important to highlight two key features in order to understand the islanding phenomenon. The first one is associated with the so-called "Non-detection zone” (NDZ). The $\mathrm{NDZ}$ can be defined as the range (in terms of the power difference between the DG inverter and the load or load parameters) in which an islanding detection scheme under test fails to detect this condition [10]. The second feature is associated with the type of loads (potential loads inside an isle), which can be modelled as a parallel RLC circuit. This circuit is primarily used because it raises more difficulties for islanding detection techniques than others. Generally, non-linear loads that produce current harmonics, or constant power loads do not represent significant problems for islanding detection [11].

The passive techniques are based on islanding detection through monitoring of some parameters such as voltage, current, frequency and/or their characteristics. Those techniques interrupt the inverter operation when there is a transition beyond the limits established for these parameters. They have the advantage of not worsening the quality of power, but exhibit a considerable NDZ. The main passive techniques are: Over/under-voltage and over/under-frequency [11], [12], Phase Jump Detection [11], [13], Detection of voltage and current harmonics [10], [11], [14], and Detection based on state estimators [15].

The active techniques intentionally introduce disturbances at the output of the inverter to determine if they affect the voltage, frequency or impedance parameters, in which case it is assumed that the grid has been disconnected and the inverter is isolated from the load.

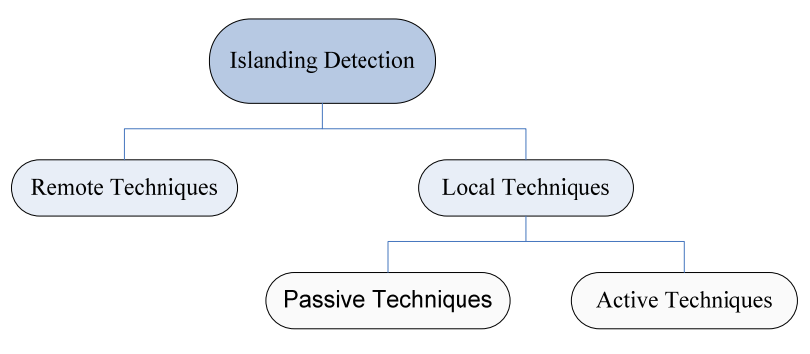

Fig. 1. Anti-islanding techniques classification.

Active techniques have the advantage of remarkably reducing or even eliminating the NDZ, but in order to achieve their purpose they may deteriorate the quality of the current injected to the grid or even cause instability.

Among the active techniques, the following can be pointed out: Impedance measurement [11], [16], [17], Harmonic injection/detection of impedance [18], Sliding Mode Frequency Shift (SMS) [19], [20], Active Frequency Drift (AFD) [11], [19], [20], Frequency jump [11], [21], Sandia Frequency Shift (SFS) Sandia Voltaje Shift (SVS) [11], [19], [22], 
[23], [26], Mains Monitoring Units with Allocated All-pole Switching Devices Connected in Series (MSD)[11],

Variation of active power and reactive power [10], [24], [25], [26], and General Electric Frequency Schemes (GEFS)

[20], [25].

Other detection techniques are based on communication between the grid and the DGs. They are more reliable than the local techniques but more expensive to implement and, therefore, less profitable. Here are some of these techniques: Impedance Insertion [11], [29], Power Line Carrier Communications [11], [30], [31], Signal Produced by Disconnect [11], Supervisory Control and Data Acquisition (SCADA) [11], [32].

This paper presents a new active technique based on the Goertzel algorithm [33] to detect islanding.

\section{SINGLE PHASE INVERTER}

Figure 2 shows the scheme of the 230W single-phase inverter that has been used to evaluate the islanding detection algorithm. The inverter is fed by a programmable DC source in which the I-V curve of a PV panel array has been programmed. The maximum power point (MPP) of the I-V curve takes place at the following operation point: $P_{P V \_M P P}=230 \mathrm{~W}, V_{D C_{-} M P P}=400 \mathrm{~V}$. For DC-AC conversion a current-controlled H-bridge inverter with bipolar PWM [34] and an output LCL filter [35], [36] has been chosen. Table 1 shows the electrical parameters of the inverter under study.

Table 1. Electrical parameters of the inverter under study

\begin{tabular}{lc}
\hline \multicolumn{1}{c}{ Parameter } & Values \\
\hline Power injected from the DC source $\left(P_{p v M P P}\right)$ & $230 \mathrm{~W}$ \\
DC_LINK voltage $\left(V_{D C} M P P\right.$ & $400 \mathrm{~V}$ \\
Inverter output voltage $\left(V_{O \_} R M S\right.$ & $230 V_{R M S} \pm 10 \%$ \\
Inverter output fundamental frequency $\left(f_{g}\right)$ & $50 \mathrm{~Hz}$ \\
Inverter inductance $(L)$ & $37 \mathrm{mH}$ \\
Inverter output capacitor $(C)$ & $270 \mathrm{nF}$ \\
Damping resistance $\left(R_{d}\right)$ & $50 \Omega$ \\
Grid inductance $\left(L_{\text {grid }}\right)$ & $1.8 \mathrm{mH}$ \\
Inverter switching frequency $\left(f_{s i}\right)$ & $20 \mathrm{kHz}$ \\
\hline
\end{tabular}
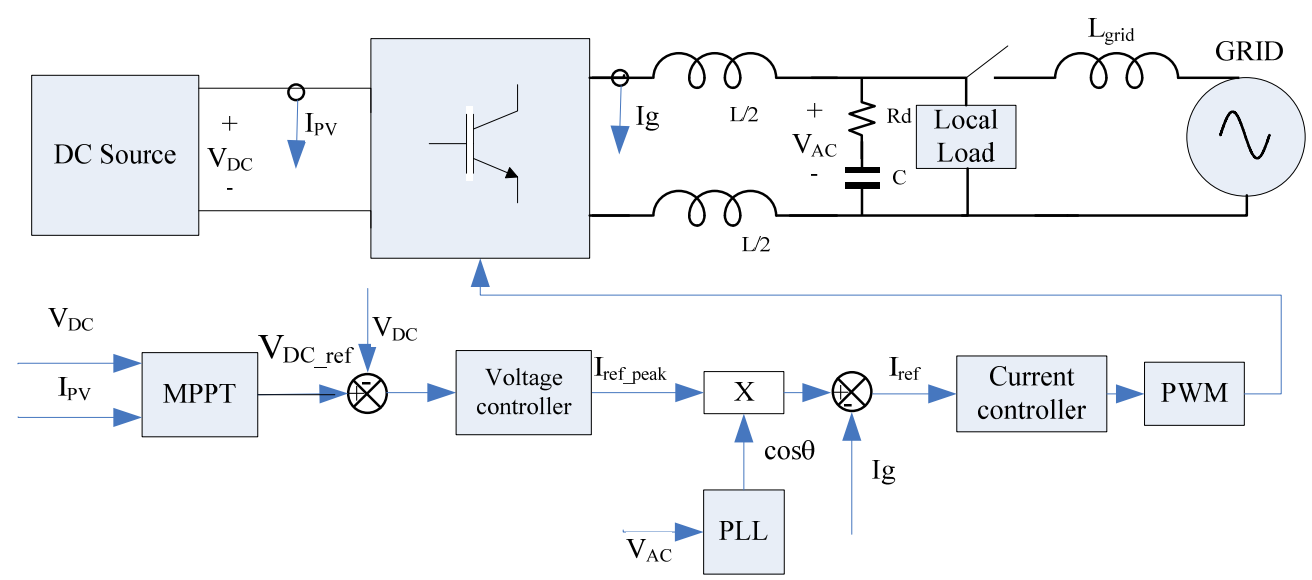

Fig. 2. Block diagram of the inverter.

As it can be observed from Figure 2, the control of the inverter starts from a maximum power point tracker (MPPT), implemented by means of a P\&O (perturb and observe) algorithm [37], [38]. The output of the MPPT, $V_{D C_{-} r e f}$, is the 
reference of the PV string voltage, $V_{D C}$. The PWM inverter has an inner current controller based on a harmonic compensator [38] in order to comply with the IEEE 929-2000 standard [40], in terms of the THD of the current injected to the grid. The amplitude, $\mathrm{I}_{\mathrm{ref}}$, of the current loop reference is the output of the PI controller of the inverter DC_link voltage, that is synchronized with the fundamental component of the grid voltage by means of a phase locked loop (dqPLL) implemented using the synchronous rotating reference frame technique [41], [42]. Figure 3 shows the dqPLL block diagram.

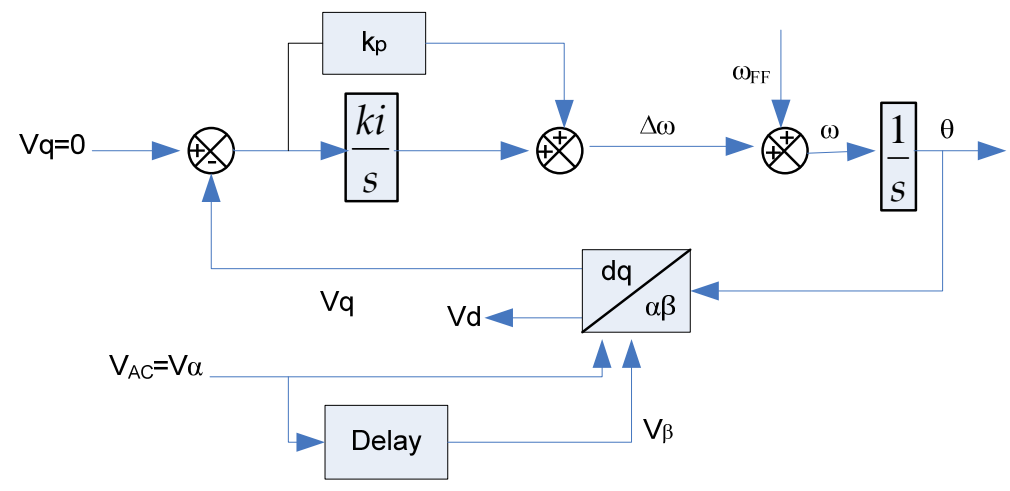

Fig. 3. Block diagram of the dqPLL.

Table 2 shows the expression of the regulators chosen for the present study, for both the inner current loop and the outer voltage loop, along with the resulting crossover frequencies and phase margins of both loops.

Table 2. Expressions of the chosen regulators and resulting crossover frequencies and phase margins

\begin{tabular}{lcrr}
\hline & Inverter & & \\
\hline Controller & Expression of the transfer function (continuous time) & Crossover & Phase \\
frequency & $1.15 k H z$ & $50^{\circ}$ \\
\hline Current controller & $k_{P}+\frac{k_{h} \cdot B_{h} \cdot s}{s^{2}+B_{h} \cdot s+\left(\omega_{h}^{2}\right)}=0.5+\frac{100 \cdot 2 \pi \cdot s}{s^{2}+2 \pi \cdot s+(100 \pi)^{2}}$ & & $88.6^{\circ}$ \\
$\qquad k_{P}+\frac{k_{i}}{s}=4.8+\frac{0.33}{s}$ & & & \\
\hline
\end{tabular}

\section{ANTISLANDING METHOD BASED ON THE GOERTZEL ALGORITHM.}

\section{a. GENERATION OF THE DISTURBANCE}

The proposed method is based on the addition of a current harmonic to the inverter current reference [18]. The perturbation is generated by the modification the phase signal of the PLL, so that the angle of the inverter current reference, $\theta_{I N V}$, is changed according to (1), where $\mathrm{k}$ is the rate of disturbance introduced into the system. The main advantage of using the PLL to generate the disturbance is that the disturbance always remains proportional to the 
injected current and as discussed below it does not affect the zero-crossings of the signal. The scheme of the PLL perturbation is shown in Figure 4.

$$
\theta_{I N V}=\theta_{F P L L}+k \cdot \cos \left(\theta_{F P L L}\right)
$$

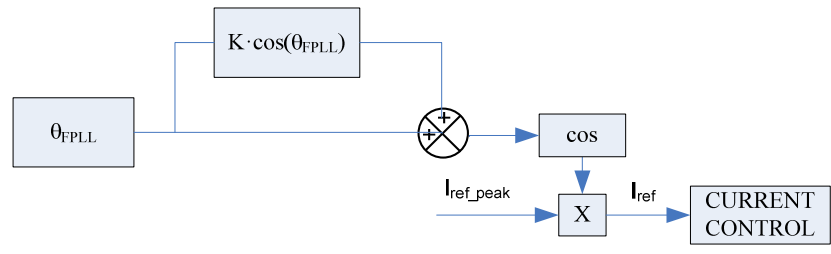

Fig. 4. Proposed PLL perturbation.

The upper plot of Figure 5 depicts the ideal, $\theta_{F P L L}$, and the distorted, $\theta_{I N V}$, output phase waveform of the PLL. The lower

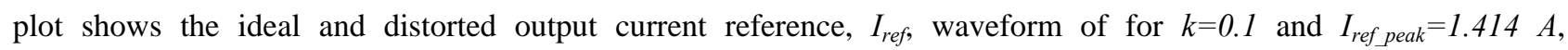
corresponding to $230 \mathrm{~W}$ at $V_{O_{-} R M S}=230 \mathrm{~V}$. The effect of (1) is to modify the inverter output current waveform, introducing a second harmonic, as it will be demonstrated in the following.
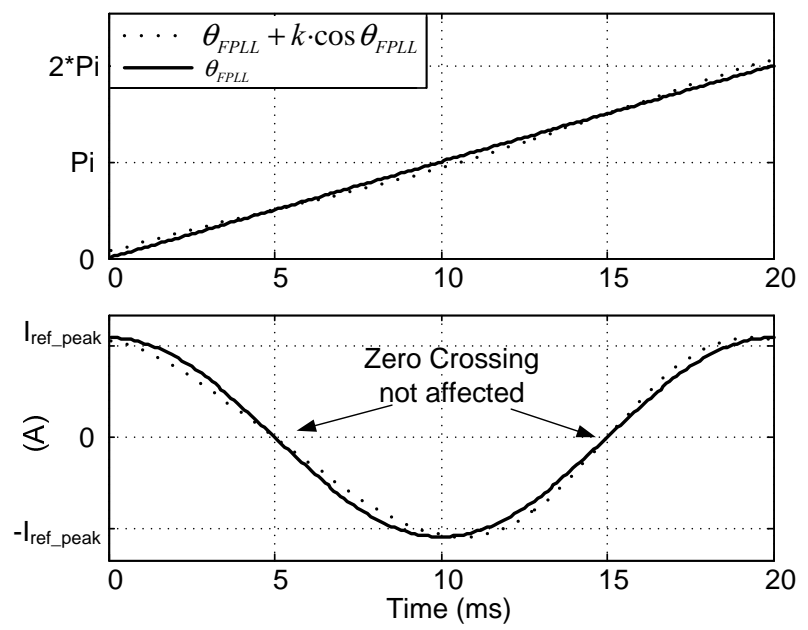

Fig. 5. Up: Ideal, $\theta_{\mathrm{FPLL}}$, and distorted, $\theta_{\mathrm{INV}}$, output phase waveform of the PLL. Low: ideal and distorted output current reference, $\mathrm{I}_{\mathrm{ref}}$, waveform of for $k=0.1$ and $I_{\text {ref_peak }}=1.414 \mathrm{~A}$.

The injected signal waveform is defined by (2):

$$
\sigma_{i n j}=k \cdot \cos \theta_{F P L L}
$$

The resulting inverter current phase reference is given by (3):

$$
\cos \theta_{I N V}=\cos \left(\theta_{I N V}+\sigma_{i n j}\right)=\cos \left(\theta_{F P L L}+k \cdot \cos \theta_{F P L L}\right)
$$

Applying the trigonometric rule (4) to (3) it results (5):

$$
\begin{aligned}
& \cos (A+B)=\cos (A) \cdot \cos (B)-\sin (A) \cdot \sin (B) \\
& \cos \left(\theta_{F P L L}+k \cdot \cos \theta_{F P L L}\right)= \\
& \cos \left(\theta_{F P L L}\right) \cdot \cos \left(k \cdot \cos \theta_{F P L L}\right)-\sin \left(\theta_{F P L L}\right) \cdot \sin \left(k \cdot \cos \theta_{F P L L}\right)
\end{aligned}
$$

Assuming that $\mathrm{k}<<1$ the approximation (6) results, which can be applied to (5) resulting in (7). 


$$
\begin{aligned}
& \sin \left(k \cdot \cos \theta_{F P L L}\right) \approx k \cdot \cos \theta_{F P L L}, \text { for } k<<1 \\
& \cos \left(k \cdot \cos \theta_{F P L L}\right) \approx 1, \text { for } k<<1 \\
& \cos \left(\theta_{I N V}\right) \approx \cos \theta_{F P L L}-k \cdot \sin \theta_{F P L L} \cdot \cos \theta_{F P L L}
\end{aligned}
$$

Taking into account (8), we can rewrite (7) as (9):

$$
\begin{aligned}
& \sin (2 \cdot \theta)=2 \cdot \sin (\theta) \cdot \cos (\theta) \\
& \cos \theta_{I N V} \approx \cos \theta_{F P L L}-\frac{k}{2} \cdot \sin \left(2 \cdot \theta_{F P L L}\right)
\end{aligned}
$$

As it is demonstrated by (9), the addition of the term $\sigma_{i n j}=K \cdot \cos \theta_{F P L L}$ as described by (3), produces a second harmonic in the inverter current reference signal for small values of $k(k<<1)$.

As a result, a small distortion of the inverter current reference is expected, as shown in Figure 5.

Note that the inverter current reference waveform is not affected at the zero crossings, whereas its peak values are shifted in time but not modified.

When the grid is connected, the voltage at the PCC is imposed by the grid and its waveform is not altered by the proposed islanding detection algorithm. When the grid is not present (islanding situation), the PCC voltage follows the waveform of the current injected by the inverter. The proposed islanding detection method is based on measuring the second harmonic of the PCC voltage waveform by means of the Goertzel algorithm.

\section{b. DETECTION ALGORITHM}

The Goertzel algorithm [33] enables an individual Discrete Fourier Transform (DFT) coefficient to be generated using a simple recursive filter which incorporates a second-order digital resonator. Its inherent simplicity and reduced computational effort has in recent years raised the interest in second-order digital resonators and Goertzel filters which generate Fourier coefficients, or detect tones, at arbitrary frequencies rather than just at the DFT frequencies [43]. Among the Goertzel algorithm applications in the electric power area are the detection of induction motor speed [44] and quality control systems interconnected to the power grid [45].

In this work the Goertzel algorithm will be applied for the measurement of the second harmonic amplitude enabling islanding detection. As the algorithm only requires the analysis of a single frequency component, its processing time will be shorter than that of the algorithms that use a group of frequencies.

Moreover, the Goertzel algorithm, compared with the direct calculation of an N-point DFT, reduces the number of operations. Compared to the N-point DFT, the Goertzel algorithm uses half the computational time, fewer multiplications, the same number of additions, and requires approximately the number of trigonometric evaluations of the DFT divided by N, which is its greatest advantage [33]. 
The equation representing the Goertzel algorithm is given by a transfer function instead of by a second order IIR filter. The z-domain transfer function of the Goertzel filter is expressed by (10).

$$
H(z)=\frac{1-e^{-j \frac{2 \pi \cdot k_{g}}{N}} z^{-1}}{1-2 \cdot \cos \left(\frac{2 \pi \cdot k_{g}}{N}\right) \cdot z^{-1}+z^{-2}}
$$

In the frequency domain the term $k_{g}$ represents an integer number in the range: $0 \leq k_{g} \leq N-1$.

The magnitude $\left(y_{k g}\right)$ and phase $(\theta)$ of the required frequency component can be found from the Goertzel algorithm, according to the expressions (11) and (12), respectively. Where $v_{k g}$ is the vector of the discretized measurement of the voltage at the PCC.

$$
\begin{aligned}
& \left|y_{k_{g}}(N)\right|=v_{k_{g}}^{2}(N-1)+v_{k_{g}}^{2}(N-2)-v_{k_{g}}(N-1) \cdot v_{k_{g}}(N-2) \cdot \cos \left(\frac{2 \pi \cdot k_{g}}{N}\right) \\
& \theta=\arg \left\{y_{k_{g}}(N)\right\}=\arctan \frac{\sin \left(\frac{2 \pi \cdot k_{g}}{N}\right) \cdot v_{k_{g}}(N-2)}{v_{k_{g}}(N-1)-\cos \left(\frac{2 \pi \cdot k_{g}}{N}\right) \cdot v_{k_{g}}(N-2)}
\end{aligned}
$$

In order to implement the Goertzel algorithm to determine the second harmonic amplitude it is necessary to discretize the inverter output voltage signal at the PCC. This discretization has been performed at $1 \mathrm{kHz}(20$ points per cicle), as shown in Figure 6.

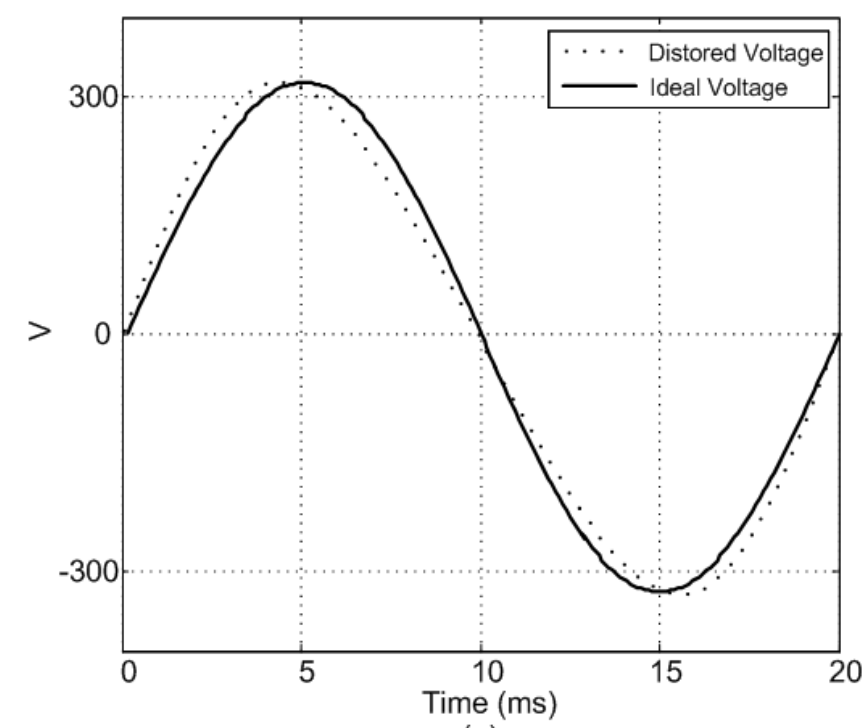

(a)

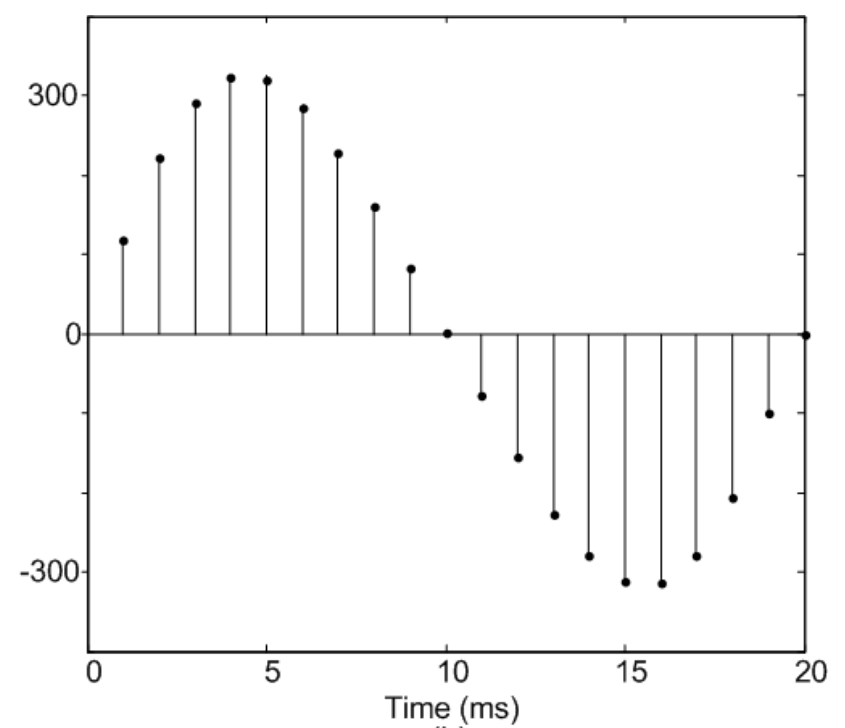

(b)

Fig. 6(a) Output voltage (ideal and distorted), (b) Discretized distorted voltage signal

After calculating the amplitude of the second harmonic from equation (11), it is low pass filtered (50 $\mathrm{Hz})$, yielding an averaged variable, $A y_{k}$. This variable is compared with a threshold value in order to determine whether the system is in an islanding situation. 


\section{c. THRESHOLD CALCULATION}

Some parameters of the system must be taken into account to calculate the detection threshold such as the grid impedance, the load impedance and the power injected by the inverter. A mathematical analysis of the effect of disturbing the system with a second harmonic current is presented in this subsection.

On one hand, the detection threshold of the second harmonic of the PCC voltage must be set higher than the second harmonic voltage produced by the inverter at the PCC when the grid is connected, in order to avoid false islanding detections. On the other hand, there is an upper limit for the detection threshold as will be explained later.

In order to find the lower limit for the detection threshold, it is considered that the grid is weak (high grid impedance), which constitutes the worst case for the analysis, because in a strong grid a second harmonic disturbance or a load with second-order harmonic contents affects less the voltage waveform at the PCC before the islanding situation.

The grid impedance is calculated starting from the base impedance of the system under study: $Z_{b}=5.29 \Omega$, having considered the base power of the system: $S_{b}=10 \mathrm{kVA}$. For a weak grid the grid impedance, $Z_{g}$, might be considered as one tenth of the base impedance [46]. In this case it results: $Z_{g}=529 \mathrm{~m} \Omega$. Three different cases have been taken into account: 1) purely resistive grid $\left.\left(Z_{g}=R_{g}=529 \mathrm{~m} \Omega\right), 2\right)$ purely inductive grid $\left(L_{g}=1.8 \mathrm{mH}\right)$, and 3) a combination of both ( $R_{\text {grid }}=374 \mathrm{~m} \Omega$ and $\left.L_{\text {grid }}=1.2 \mathrm{mH}\right)$.

From Fig. 4 and (9) it is found that the inverter output current is defined by (13), supposing a good tracking of the current loop.

$i_{\text {ref }}=I_{\text {ref_peak }} \cdot \cos \theta_{I N V} \approx I_{\text {ref_peak }}\left(\cos \theta_{F P L L}-\frac{k}{2} \cdot \sin \left(2 \cdot \theta_{F P L L}\right)\right)$

Therefore, the amplitude of the second harmonic of the inverter output current is expressed by (14).

$i_{100 \mathrm{~Hz}} \approx I_{\text {ref_peak }} \cdot \frac{k}{2} \cdot \sin \left(2 \cdot \theta_{F P L L}\right)$

Figure 7 presents the equivalent circuit of the system behavior at $100 \mathrm{~Hz}$ when the grid is connected, being $\vec{V}_{g_{-} 100 \mathrm{~Hz}}$ the $100 \mathrm{~Hz}$ harmonic of the grid voltage. The term $\vec{I}_{100 \mathrm{~Hz}}$ stands for the $100 \mathrm{~Hz}$ harmonic injected by the inverter according to the proposed islanding detection method.

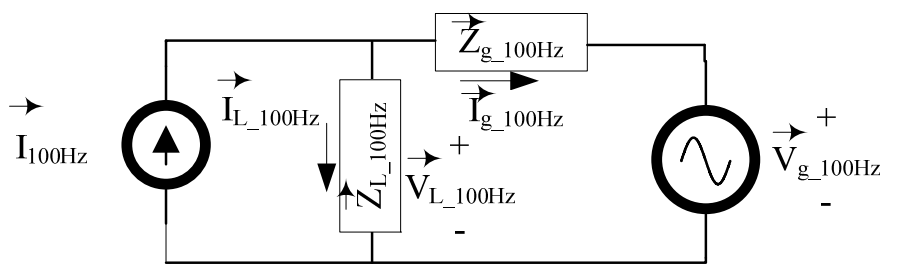

Fig. 7 Equivalent circuit of the system at $100 \mathrm{~Hz}$ when the grid is connected.

The currents in the circuit of Fig. 7 follow (15) 
$\vec{I}_{100 \mathrm{~Hz}}=\vec{I}_{L_{-} 100 \mathrm{~Hz}}+\vec{I}_{g_{-} 100 \mathrm{~Hz}}=\frac{\vec{V}_{L_{-} 100 \mathrm{~Hz}}}{\vec{Z}_{L_{-} 100 \mathrm{~Hz}}}+\frac{\left(\vec{V}_{L_{-} 100 \mathrm{~Hz}}-\vec{V}_{g_{-} 100 \mathrm{~Hz}}\right)}{\vec{Z}_{g_{-} 100 \mathrm{~Hz}}}$

Even for the worst case (weak grid) it holds true that $\left|Z_{g_{-} 100 H z}\right|<<\left|Z_{L_{-}-100 H z}\right|$. Taking this fact into account and also that in usual grids the second harmonic of the grid voltage is negligible $\left(\mathrm{V}_{\mathrm{g}_{\_} 100 \mathrm{~Hz}}<<\mathrm{V}_{\mathrm{L}_{-} 100 \mathrm{~Hz}}\right)$, it results (16). Therefore, (17) is a valid approximation for the second harmonic of the PCC voltage produced by the proposed method when the grid is connected. Therefore, the threshold for islanding detection must be set above the value defined by (17), which constitutes the lower limit of the detection threshold.

$$
\begin{aligned}
& \vec{I}_{100 \mathrm{~Hz}}=\left[\frac{\vec{Z}_{L_{-} 100 \mathrm{~Hz}}+\vec{Z}_{g_{-} 100 \mathrm{~Hz}}}{\vec{Z}_{L_{-} 100 \mathrm{~Hz}} \cdot \vec{Z}_{g_{-} 100 \mathrm{~Hz}}}\right] \cdot \vec{V}_{L_{-} 100 \mathrm{~Hz}} \approx \frac{\vec{V}_{L_{-} 100 \mathrm{~Hz}}}{\vec{Z}_{g_{-} 100 \mathrm{~Hz}}} \\
& \vec{V}_{L_{-} 100 \mathrm{~Hz}} \approx \vec{Z}_{g_{-} 100 \mathrm{~Hz}} \cdot \vec{I}_{100 \mathrm{~Hz}}
\end{aligned}
$$

Besides, there is an upper limit for the detection threshold. This limit is calculated for assuring that when the grid is disconnected (islanding situation) the second harmonic of the voltage at the PCC becomes always higher than the threshold established, yielding to islanding detection. Obviously, the threshold cannot be set arbitrarily high, or islanding detection could fail in some islanding situations. In an islanding situation the expression of the second harmonic of the voltage at the PCC is given by (18). This value is a function of the load at the PCC at $100 \mathrm{~Hz}, \vec{Z}_{L_{-} 100 \mathrm{~Hz}}$.

$$
\vec{V}_{L_{-} 100 \mathrm{~Hz}} \approx \vec{Z}_{L_{-} 100 \mathrm{~Hz}} \cdot \vec{I}_{100 \mathrm{~Hz}}
$$

In accordance to the IEEE 929-2000 standard for islanding detection, the worst case to detect islanding is given for a parallel RLC load with $\mathrm{Q}=2.5$. The absolute value of the load impedance phasor for this kind of load at $100 \mathrm{~Hz}$ is calculated according to (19). Thus, the threshold for islanding detection must be set below the value defined by (18) with a load impedance given by (19).

$$
\left|Z_{L_{-} 100 H z}\right|=\frac{1}{\sqrt{\left(\frac{1}{R}\right)^{2}+\left(2 \pi \cdot 100 \cdot C-\frac{1}{2 \pi \cdot 100 \cdot L}\right)^{2}}}
$$

Besides, an improvement is introduced to provide robustness to the detection system: a delay is programmed for verification of the islanding status to prevent from false islanding detection in the presence of transients or noise in the measurements. When the averaged output of the Goertzel filter, $A y_{k}$, exceeds the threshold, this condition must be maintained for a period of time of $100 \mathrm{~ms}$ (corresponding to 5 grid cycles) before disconnection from the PCC, in order to guarantee that the islanding has been really produced. The established $100 \mathrm{~ms}$ time does not exceed the standard set by IEEE 929-2000 [47]. The algorithm of the proposed islanding detection method scheme can be seen in Figure 8. 


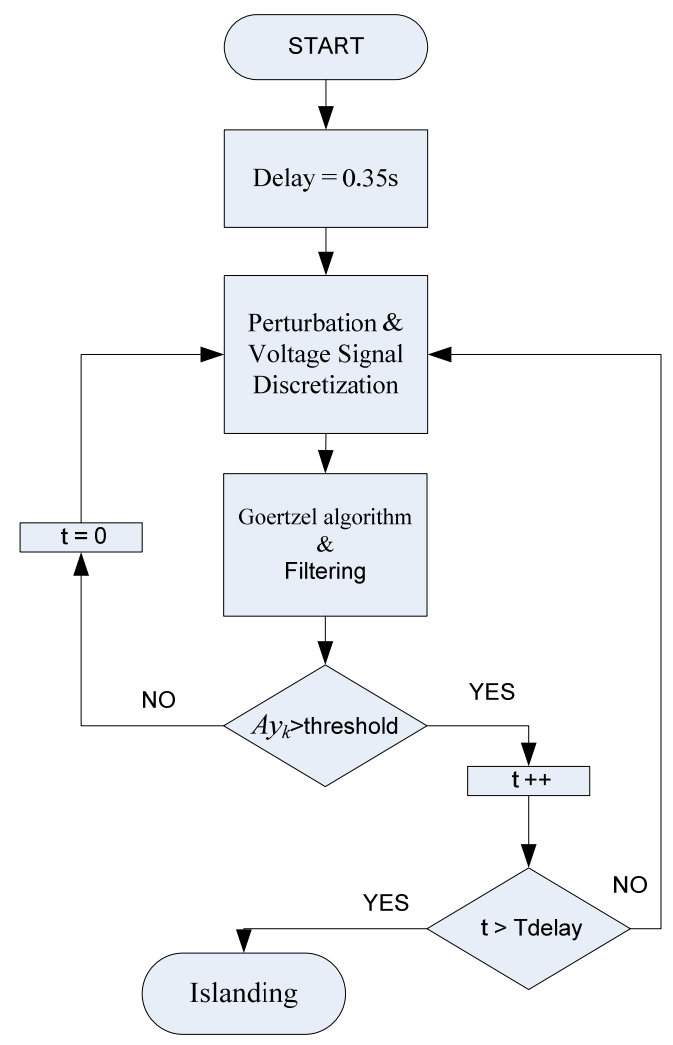

Fig. 8 Algorithm of the proposed islanding detection method.

\section{SIMULATION RESULTS}

This section shows simulation results of the above method. These simulations were conducted in PSIM ${ }^{\mathrm{TM}}$ software [48] and tested on the PV inverter and grid, both described in section II. The simulated inverter is operating in closed loop with a conventional P\&O MPPT algorithm. The tests follow the requirements of the IEEE 929-2000 standard for islanding detection. In particular, parallel RLC loads with a high Q factor often present problems for island detection. The quality factor $\mathrm{Q}$ is defined by (20).

$$
\mathrm{Q}=\mathrm{R} \sqrt{\frac{C}{L}}
$$

Simulations have been conducted with a duration of one second, with grid disconnection at the instant $t=300 \mathrm{~ms}$. The loads under test have been an RLC parallel load with $Q=3.289(R=226.67 \Omega, L=220 \mathrm{mH}, C=45 \mu F)$ and a purely resistive load $(R=226.6 \Omega)$.

Tests were performed for different values of the grid impedance (weak grid impedance and strong grid impedance), in order to corroborate the behavior of the proposed islanding technique. In all cases, the simulated detection times ranged between $103 \mathrm{~ms}$ and $104 \mathrm{~ms}$. The simulations to be shown in the following have been performed with a purely inductive weak grid: $L_{\text {grid }}=1.8 \mathrm{mH}$.

Another factor that was considered when conducting the tests was to determine whether the crossover frequencies and phase margins of the current and voltage loop of the inverter affect the proper operation of the proposed islanding 
detection technique. Two sets of current and voltage controllers were designed: 1) the set described in Table 2, with crossover frequencies of the current and voltage loop of $f_{C i}=1.15 \mathrm{kHz}$ and $f_{C v}=11.5 \mathrm{~Hz}$, respectively, and 2) faster controllers with higher crossover frequencies: $f_{C i}=1.85 \mathrm{kHz}$ (phase margin: $48.5^{\circ}$ ) and $f_{C v}=20 \mathrm{~Hz}$ (phase margin: $88.3^{\circ}$ ). The simulation results of the islanding detection technique were similar for both sets of controllers. All the simulations to be shown in the following are performed with the controllers presented in Table 2.

The simulations have been performed with different harmonics at the PCC voltage. Specifically, three different situations have been simulated: (a) an ideal purely sinusoidal grid voltage, (b) a grid with a $5 \%$ third harmonic voltage distortion, and (c) a grid voltage with a $5 \%$ fifth harmonic distortion.

Figure 9.a shows the simulation results with the RLC load with an ideal purely sinusoidal grid voltage. The upper two graphs show the evolution of the PCC voltage and of the current injected by the inverter. The bottom graph depicts the instant in which islanding occurs $(t=300 \mathrm{~ms}$ ) and when the proposed method detects it. The middle graph represents the evolution of the measured variable $H$. It can be noticed that the inverter disconnection takes place within the time defined by the standards [47]. Figures 9.b and 9.c depict the response of the proposed islanding algorithm with a distorted grid voltage. In all cases the disconnection time is less than $105 \mathrm{~ms}$.

Figure 10 shows the simulation with a R load and an ideal purely sinusoidal grid voltage. The detection time in the case of the resistive load (less than $110 \mathrm{~ms}$ ) is slightly higher than that of the RLC case.
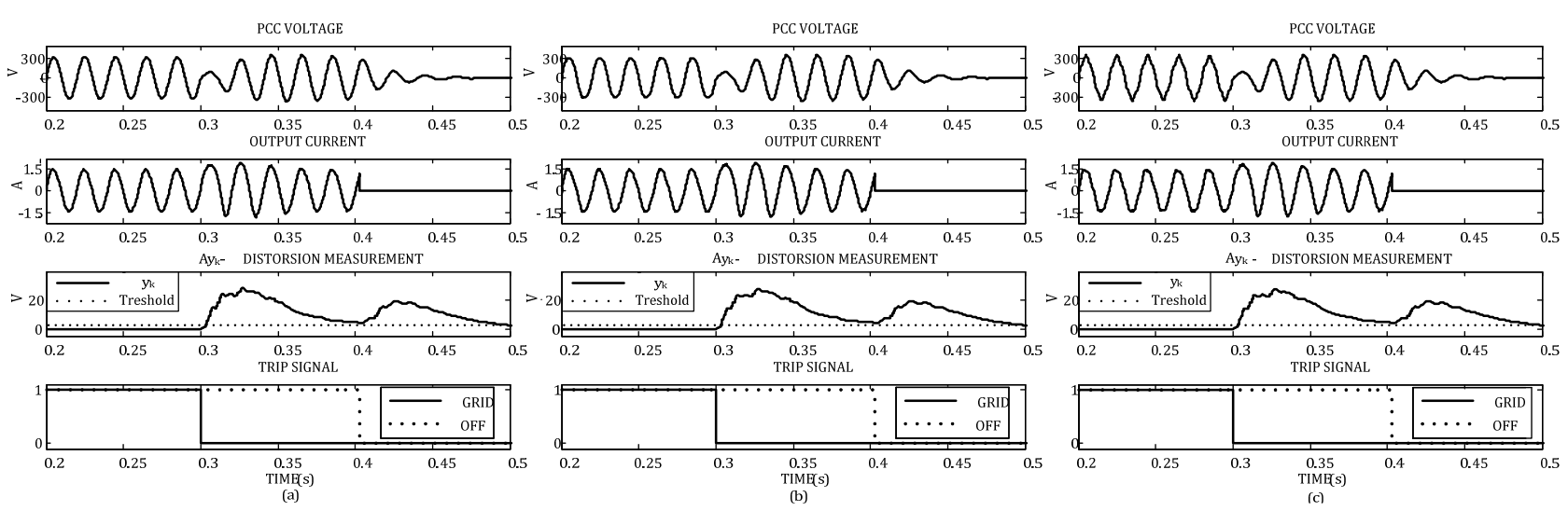

Fig. 9 Simulation results with an RLC load $(Q=3.289)$. (a) ideal purely sinusoidal grid voltage. (b) grid voltage with a $5 \%$ third harmonic distortion. (c) grid voltage with a $5 \%$ fifth harmonic distortion.
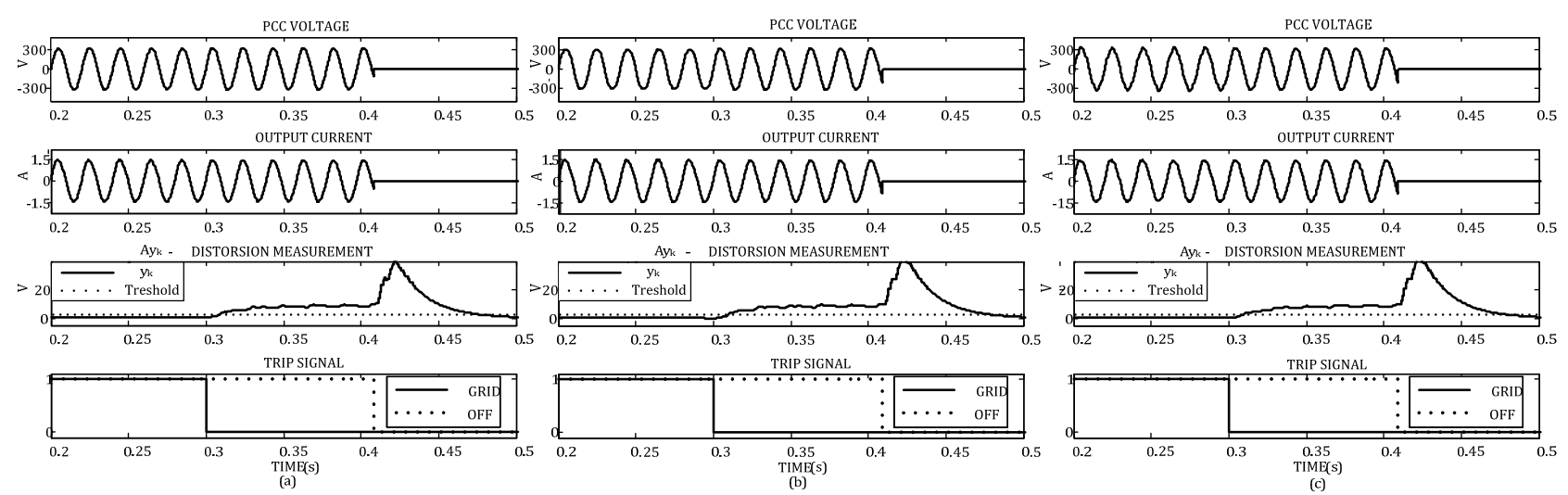
Fig. 10 Simulation results with R load. (a) ideal purely sinusoidal grid voltage. (b) grid voltage with a 5\% third harmonic distortion. (c) grid voltage with a 5\% fifth harmonic distortion.

For both kinds of loads the detection time of the method is inside the safety margin time defined by standard IEEE 9292000.

Figure 11 shows the simulation results with a nonlinear load consisting of a single phase half-wave rectifier with a capacitive filter of $47 \mu F$ in parallel with a load resistance of $450 \Omega$. The crest factor of this load is FC=3.5. It has been added to the PCC an additional resistive load of $550 \Omega$. The value of the second harmonic of the load current (rectifier+resistive load) is close to $50 \%$. The resulting disconnection time is $105 \mathrm{~ms}$.

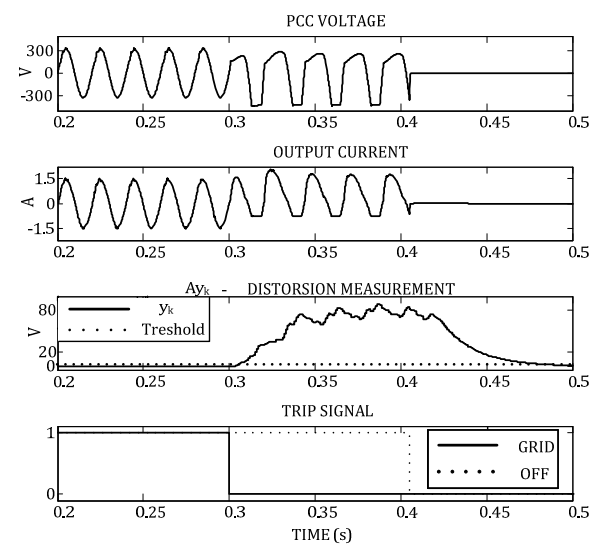

Fig. 11 Simulation results with a nonlinear load and ideal purely sinusoidal grid voltage.

Figures 12 and 13 show the simulation results with the previously described parallel $\mathrm{RLC}$ load $(Q=3.289, \mathrm{R}=226.67 \Omega$, $L=220 \mathrm{mH}, C=45 \mu \mathrm{F}$ ) and a highly distorted grid voltage ( $5 \%$ third harmonic and $5 \%$ fifth harmonic). The proposed method is compared with other islanding detection methods such as SVS [11] [19] [22] [23] [26], Active Power Variation method [10] [24] [25] [26], SFS [11] [19] and GEFS [25] [27]. In the SVS method parameter $K v$ adjusts the response time of the algorithm. In the Active Power Variation Method parameter $K v$ increases or decreases $d P$ proportionally to the voltage variation. In the SFS method $K f$ is a constant that accelerates the islanding detection. The proposed method has the shortest disconnection time among all methods, whereas its transient effect on the DC-link voltage is the smallest.
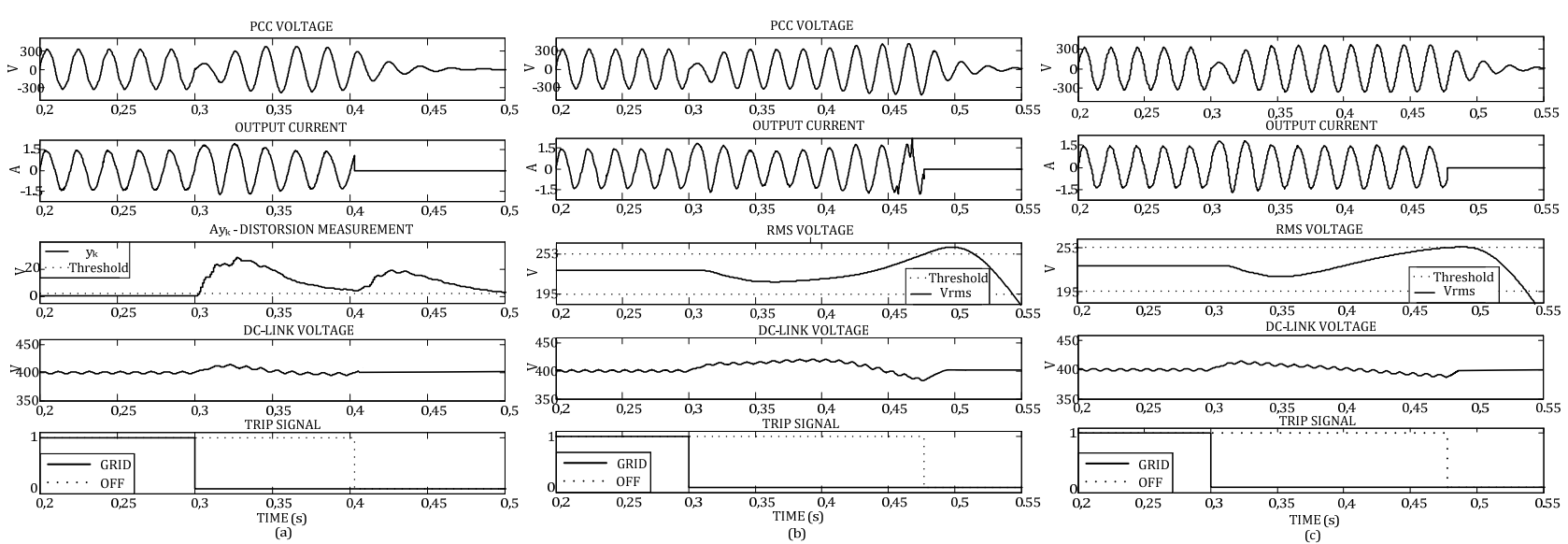
Fig. 12 Simulation results with RLC load. (a) Proposed Anti-Islanding Method. (b) SVS Method (Kv=7). (c) Active Power Variation Method $(K v=15)$
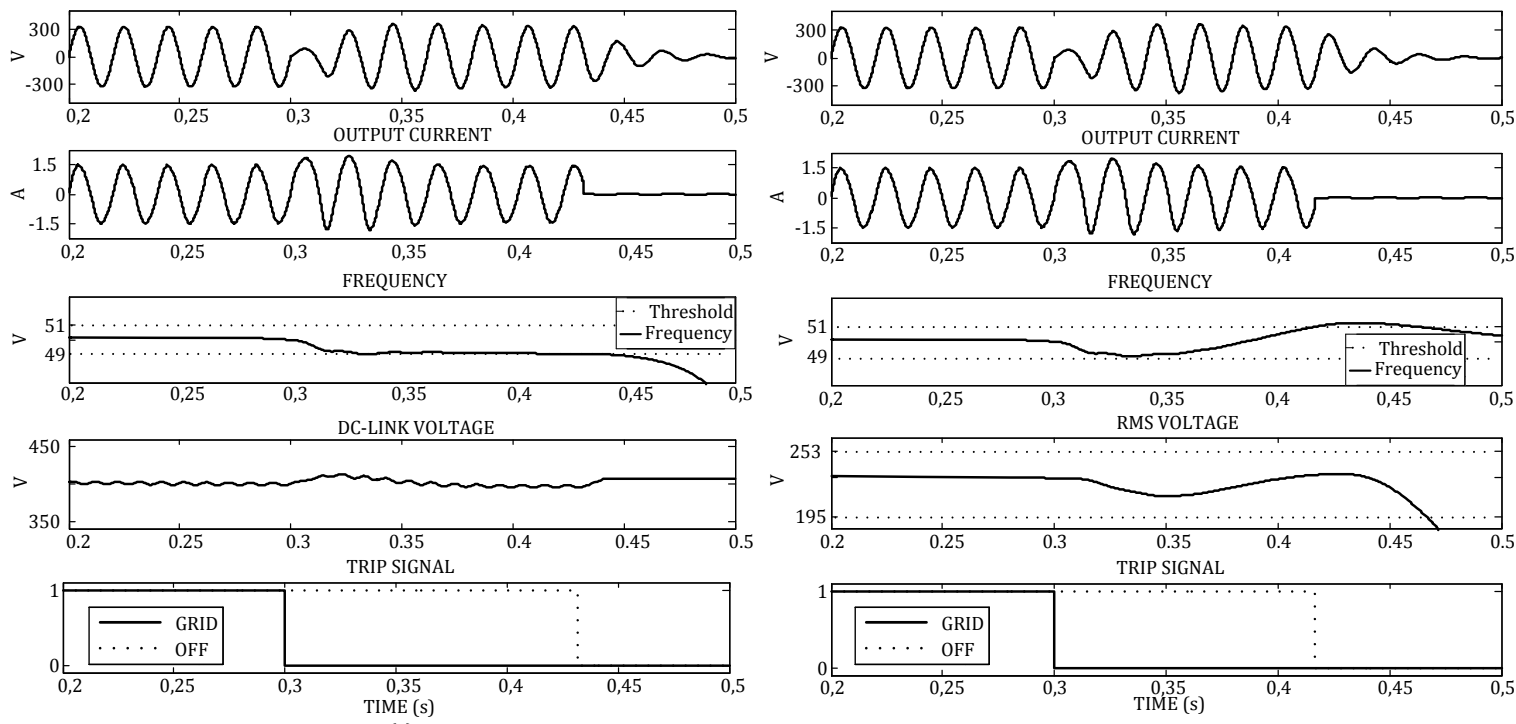

(b)

Fig. 13 Simulation results with RLC load. (a) SFS Method (Kf=8). (b) GEFS Method.

\section{EXPERIMENTAL RESULTS}

The proposed detection technique has been tested using an experimental setup where an I-V curve of a commercial PV array has been programmed on a controllable DC source AMREL SPS 800-12 DO13. The parameters of the inverter have been shown in table 1. The transfer functions of the controllers of the inverter can be found in table 2 . These controllers have been discretized by means of the Tustin method. The sampling frequency is $40 \mathrm{kHz}$. The control runs on a general purpose board designed for the DSP of Texas Intruments TMS320F2812.

Experiments were performed on a real grid voltage scenario with a $\mathrm{THD}_{\mathrm{V}}$ of $3.4 \%$ (measured up to $1.2 \mathrm{kHz}$ ) with the values shown in Figure 14, measured by means of a Fluke 43B Power Quality Analyzer.

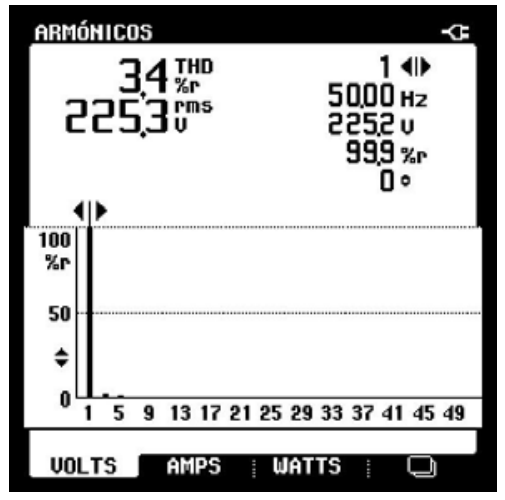

\begin{tabular}{cc}
\hline FREQUENCY & Harmonics \% \\
\hline $100 \mathrm{~Hz}$ & 0,0197 \\
\hline $150 \mathrm{~Hz}$ & 2,8194 \\
\hline $250 \mathrm{~Hz}$ & 1,8338 \\
\hline & \\
\hline$T H D_{V}$ & $3.4 \%$ \\
\hline$V_{r m s}$ & $225.3 \mathrm{~V}$ \\
\hline
\end{tabular}

Fig. 14. Grid voltage properties. 
Figure 15 (a) shows the system behavior, without disconnecting the inverter when the Islanding situation is produced, with the RLC load described in section IV. In this case the voltage and frequency perturbation of the system after the islanding situation is not detected by passive methods (Over/under-voltage and over/under-frequency). The upper two waveforms show the evolution of the current injected by the inverter and of the voltage at the local RLC load. The bottom waveform represents the instant when the islanding situation is produced. This signal goes low at the moment when the grid is disconnected from the local RLC load. In this case the inverter is allowed to feed the local load after the islanding situation. Figure 15 (b) shows the behavior of the output of the Goertzel filter, $A y_{k}$, inside a DSP variable. It is observed that the change of this magnitude is easily detectable. Despite the decrease of the PCC rms voltage and the increase of the rms output current when the grid is disconnected from the system, the PCC voltage and frequency values keep inside the levels set by the standard EN 50160, so that passive techniques would not detect the islanding situation. In this situation, the inverter would continue feeding the local loads as shown in Figure 15 (a). Therefore, an active islanding detection technique is necessary to disconnect the inverter.

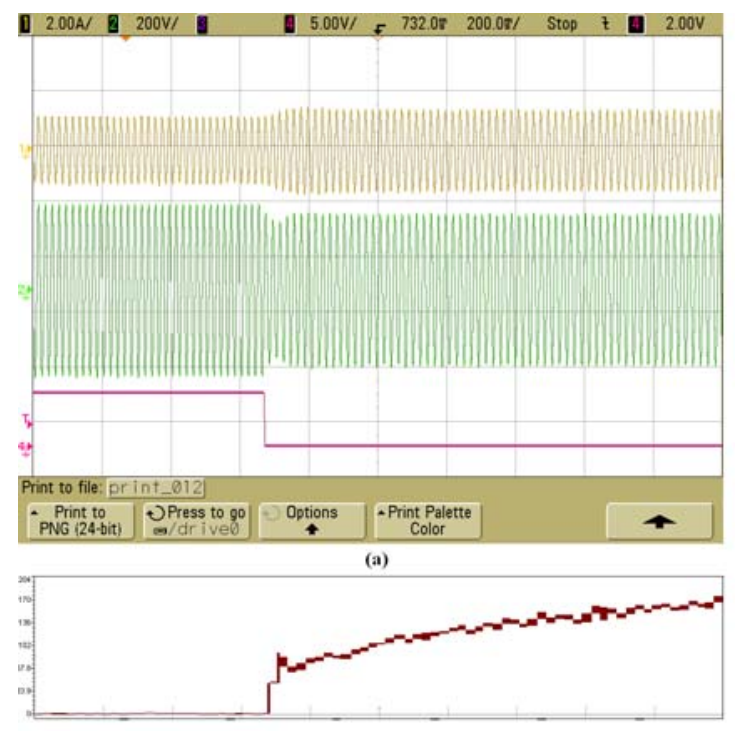

(b)

Fig. 15. (a) System behavior in islanding situation without disconnection, with RLC load. Up: inverter output current, 2 A/div. Center: Voltage at the local load, 200 V/div. Down: Grid disconnection signal, 5 V/div. Time scale: $200 \mathrm{~ms} / \mathrm{div}$. (b) Behavior of the scaled (x 3) averaged output of the Goertzel filter, $A y_{k}$, inside the DSP.

Experimental results with disconnection of the inverter after islanding detection are shown in Figure 16. Figure 16 (a) depicts the operation of the proposed method with an RLC local load with a quality factor $Q=3.289(R=226.67 \Omega, L$ $=220 \mathrm{mH}, \mathrm{C}=45 \mu \mathrm{F}$ ), as described in section IV. The upper two waveforms show the evolution of the current injected by the inverter and of the voltage at the local RLC load. The bottom waveform depicts the instant at which islanding occurs (high to low transition of this waveform). In this case the method is able to detect the islanding situation and stop the power generation in $110 \mathrm{~ms}$. In Figure 16 (b) the experimental results with an R load $(R=226.67 \Omega)$ are shown, 
yielding similar conclusions to those of Figure 16 (a). It can be observed that the detection time hardly depends on the kind of load. This detection time widely meets the safety margins established by the standard IEEE 929-2000.

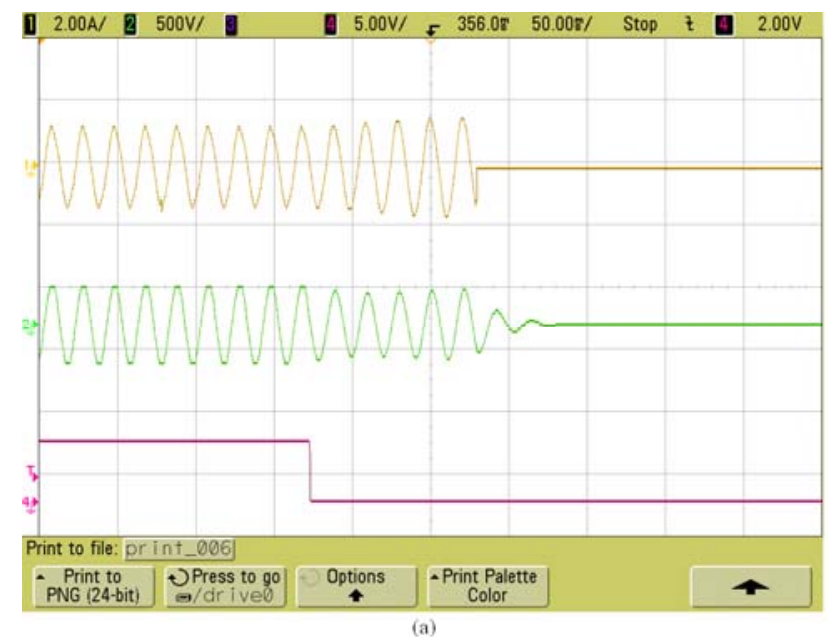

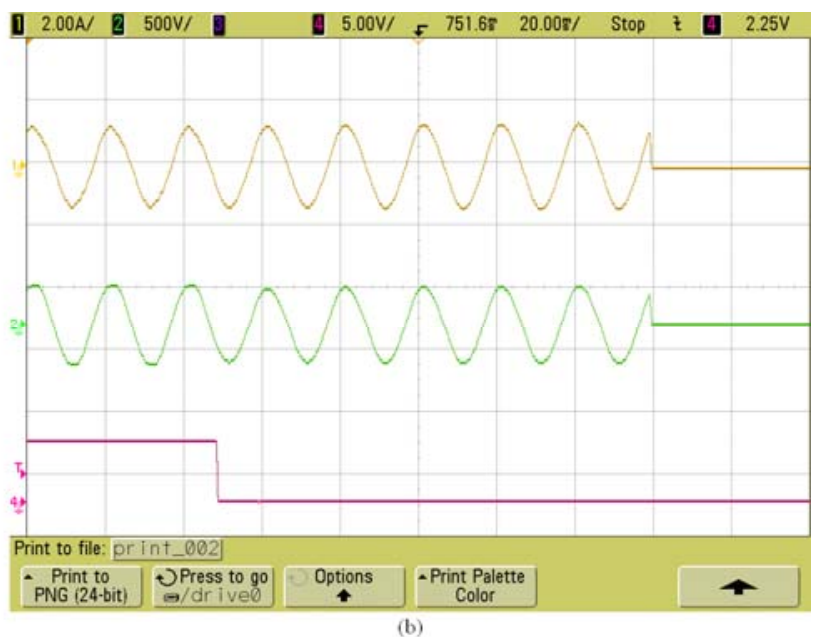

Fig. 16 Experimental results. (a) RLC Load. Up: inverter output current, $2 \mathrm{~A} / \mathrm{div}$. Center: Voltage at the local load, $500 \mathrm{~V} / \mathrm{div}$. Down:

Grid disconnection signal, 5 V/div. Time scale: $50 \mathrm{~ms} / \mathrm{div}$. (b) R Load. Up: inverter output current, $2 \mathrm{~A} / \mathrm{div}$. Center: Voltage at the local load, 500 V/div. Down: Grid disconnection signal, 5 V/div. Time scale: $20 \mathrm{~ms} / \mathrm{div}$.

The run-time of the proposed detection algorithm on the DSP is $11.2 \mu \mathrm{s}$, whereas the available computation time is 25 $\mu s$ (20 kHz switching frequency, $40 \mathrm{kHz}$ sampling frequency and double update PWM [49]), working with a $150 \mathrm{MHz}$ machine cycle. The run-time of the control loop without the detection algorithm on the DSP is $13.8 \mu \mathrm{s}$.

The distortion of the current injected by the inverter, $\mathrm{THD}_{\mathrm{i}}$, is only incremented $0.6 \%$ at full power when the disturbance of the anti-islanding algorithm is applied. The power factor is almost not affected by the anti-islanding method.

Table 3 shows a comparison of the trip time in the inverter under study with several active anti-islanding methods presented in the literature [25], [50].

Table 3. Trip time in the inverter under study with several active anti-islanding methods

\begin{tabular}{ll}
\hline \multicolumn{1}{c}{ Method } & \multicolumn{1}{c}{ Trip time } \\
\hline Active power variation & $0.3 s$ with $K v=10$ \\
Reactive power variation & $0.65 s$ with $K_{f}=60$ \\
Current Harmonic Injection & $0.1-0.2 s$ in function of set threshold \\
GEFs & $0.2 s$ \\
PLL Perturbation (proposed) & $\mathbf{0 . 1 0 5}$ to $\mathbf{0 . 1 1 5 ~} \mathrm{s}$ \\
\hline
\end{tabular}

\section{CONCLUSIONS}

A new islanding detection method has been proposed based on adding a small second harmonic disturbance to the current injected by the inverter in distributed power generation systems. When the grid is disconnected (islanding situation), the PCC voltage follows the waveform of the current injected by the inverter, so that a small voltage second harmonic can be detected. The proposed islanding detection method is based on measuring this second harmonic of the 
PCC voltage waveform by means of the Goertzel algorithm. The method is validated by means of both simulation and experimental results on a 230W single phase inverter. A distorted grid voltage has been considered. The proposed method works well even with high quality factor local loads.

The advantages of the proposed method are the following:

- An insignificant perturbation is injected in steady state, which does not affect the grid stability. The inverter injects neither significant current harmonics nor reactive power when using this method.

- Similar results with any type of load (R, RLC ...).

- Small detection times (less than 120ms).

- The method works well even if there is a huge second order harmonic load current, up to values close to 55\%.

\section{REFERENCES}

[1] Sozer, Y.; Torrey, D.A.; , "Modeling and Control of Utility Interactive Inverters," Power Electronics, IEEE Transactions on , vol.24, no.11, pp.2475-2483, Nov. 2009

[2] Timbus, A.; Liserre, M.; Teodorescu, R.; Rodriguez, P.; Blaabjerg, F.; , "Evaluation of Current Controllers for Distributed Power Generation Systems," Power Electronics, IEEE Transactions on , vol.24, no.3, pp.654-664, March 2009

[3] Mohamed, Y.; El-Saadany, E.F.; , "Adaptive Decentralized Droop Controller to Preserve Power Sharing Stability of Paralleled Inverters in Distributed Generation Microgrids," Power Electronics, IEEE Transactions on , vol.23, no.6, pp.2806-2816, Nov. 2008

[4] Serban, E.; Serban, H.; , "A Control Strategy for a Distributed Power Generation Microgrid Application With Voltage and Current Controlled Source Converter," Power Electronics, IEEE Transactions on , vol.PP, no.99, pp.1-1, 0

[5] V. Task, Evaluation of islanding detection methods for photovoltaic utility-interactive power systems, Technical Report IEAPVPS T5-09:2002, March 2002.

[6] C.L. Chen; Y. Wang; J.S. Lai; Y.S. Lee, D. Martin , Design of Parallel Inverters for Smooth Mode Transfer Microgrid Applications, Power Electronics, IEEE Transactions on , vol.25, no.1, pp.6-15, Jan. 2010

[7] Yun Wei Li, Ching-Nan Kao, An Accurate Power Control Strategy for Power-Electronics-Interfaced Distributed Generation Units Operating in a Low-Voltage Multibus Microgrid, Power Electronics, IEEE Transactions on , vol.24, no.12, pp.2977-2988, Dec. 2009

[8] J.M. Guerrero, J.C. Vasquez, J. Matas, M. Castilla, L.G. de Vicuna, Control Strategy for Flexible Microgrid Based on Parallel Line-Interactive UPS Systems, Industrial Electronics, IEEE Transactions on , vol.56, no.3, pp.726-736, March 2009

[9] P.Mahat, Z. Chen, B. Bak-Jensen, Review of islanding detection methods for distributed generation, Electric Utility Deregulation and Restructuring and Power Technologies, 2008. DRPT 2008. Third International Conference on, vol., no., pp.2743-2748, 6-9 April 2008.

[10] F. De Mango, M. Liserre, A.D. Aquila, A. Pigazo, Overview of Anti-Islanding Algorithms for PV Systems. Part I: Passive Methods, Proc. of the 12th International Conference on Power Electronics and Motion Control EPE-PEMC 2006., pp.1878-1883, Slovenia.

[11] Report IEAPVPS T5-09. Evaluation of islanding detection methods for photovoltaic utility interactive power systems, International Energy Agency Implementing agreement on Photovoltaic Power Systems, 2002, U.S.A

[12] P. Mahat, C. Zhe, B. Bak-Jensen, Review of islanding detection methods for distributed generation. Proc of the 3rd International Conference on Electric Utility Deregulation and Restructuring and Power Technologies, 2008, pp. 2743-2748, China.

[13] H. Kobayashi, K. Takigawa , E. Hashimoto, Method for Preventing Islanding Phenomenon on Utility Grid with a Number of Small Scale PV Systems, Proc. of the 21st IEEE Photovoltaic Specialists Conference, 1991, pp. 695-700, U.S.A.

[14] S. Jang, K. Kim, An islanding detection method for distributed generations using voltage unbalance and total harmonic distortion of current, IEEE Trans. on Power Delivery, 2004, Vol. 19, No. 2, pp. 745-752.

[15] M. Liserre, A. Pigazo, A. Dell'Aquila, V.M. Moreno, An Anti-Islanding Method for Single-Phase Inverters Based on a Grid Voltage Sensorless Control, IEEE Trans. on Industrial Electronics, 2006, Vol. 53, No. 5, pp. 1418-1426.

[16] M. Ropp, J. Ginn, J. Stevens, W. Bower, S. Gonzalez,. Simulation and Experimental Study of the Impedance Detection Anti-Islanding Method in the Single-Inverter Case, Proc. of the 4th World Conference of the IEEE on Photovoltaic Energy Conversion, 2006, Vol.2, pp.2379-2382,

[17] M. Ciobotaru, R. Teodorescu and F. Blaabjerg, A new singlephase PLL structure based on second order generalized integrator, in Record of IEEE PESC 2006, Jeju, Korea, p. 1511-1516.

[18] M. Ciobotaru, V. Agelidis and R. Teodorescu, Accurate and less-disturbing active anti-islanding method based on PLL for grid-connected PV Inverters. Power Electronics Specialists Conference, 2008. PESC 2008. IEEE, pp.4569-4576, June, 2008

[19] L.A.C. Lopes, S. Huili, Performance assessment of active frequency drifting islanding detection methods, IEEE Trans. on Energy Conversion, 2006, Vol. 21, No. 1, pp. $171-180$.

[20] S. Huili, L.A.C. Lopes, L. Zhixiang, Analysis and comparison of islanding detection methods using a new load parameter space, Proc. of the 30th Annual Conference of the IEEE Industrial Electronics Society IECON 2004, Vol. 2, pp. 1172 - 1177, Korea.

[21] V. Menon, M.H. Nehrir, A Hybrid Islanding Detection Technique Using Voltage Unbalance and Frequency Set Point, IEEE Trans. on Power Systems, 2007, Vol. 22, No. 1, pp. $442-448$.

[22] X. Wang, W. Freitas, W. Xu, V. Dinavahi, Impact of DG Interface Controls on the Sandia Frequency Shift Antiislanding Method, IEEE Trans. on Energy Conversion, 2007, Vol. 22, No. 3, pp. $792-794$.

[23] V. John, Z. Ye, A. Kolwalkar, Investigation of anti-islanding protection of power converter based distributed generators using frequency domain analysis, IEEE Trans. on Power Electronics, 2004, Vol. 19, No. 5, pp. 1177 - 1183.

[24] C. Jeraputra, P.N. Enjeti, Development of a robust anti-islanding algorithm for grid interconnection of distributed fuel cell powered generation, IEEE Trans. on Power Electronics, 2004, Vol.19, No.5, pp. 1163 -1170.

[25] Z. Ye, L. Li, L. Garces, C. Wang, R. Zhang, M. Dame, R. Walling, N. Miller, A new family of active antiislanding schemes based on DQ implementation for grid-connected inverters, Proc. of the 35th Annual IEEE Power Electronics Specialists Conference PESC 2004, pp. 235-241, Germany.

[26] H. Jou; W. Chiang; J. Wu, A Simplified Control Method for the Grid-Connected Inverter With the Function of Islanding Detection, Power Electronics, IEEE Transactions on, Nov. 2008, vol.23, no.6, pp.2775-2783,

[27] Z. Ye, A. Kolwalkar, Y. Zhang, P. Du; R. Walling, Evaluation of anti-islanding schemes based on nondetection zone concept, Power Electronics, IEEE Transactions on, Volume 19, Issue 5, pages: $1171-1176$, Sept. 2004. 
[28] H.H. Zeineldin, A Q- f Droop Curve for Facilitating Islanding Detection of Inverter-Based Distributed Generation, Power Electronics, IEEE Transactions on , vol.24, no.3, pp.665-673, March 2009

[29] K. Hotta, A. Kitamura, M. Okamoto, K. Takigawa, H. Kobayashi, Y. Ariga, Islanding prevention measures: demonstration testing at Rokko test center for advanced energy systems, Proc. of the 23rd Annual IEEE Power Electronics Specialists Conference PESC 1993, pp. 1063-1067, Spain

[30] M. Ropp, K. Aaker, J. Haigh, N. Sabhah, Using Power Line Carrier Communications to Prevent Islanding, Proc. of the 28th IEEE Photovoltaic Specialist Conference, 2000, pp. 1675-1678, U.S.A.

[31] W. Xu, G. Zhang, Li, W. Wang, G. Wang, \& J. Kliber, A power line signaling based technique for anti-islanding protection of distributed generators_-part I: scheme and analysis, IEEE Trans. on Power Delivery, 2007, Vol. 22, No. 3, pp. 1758-1766.

[32] T. Funabashi, K. Koyanagi, R. Yokoyama, A review of islanding detection methods for distributed resources, Proc. of IEEE Power Tech 2003, Vol.2, pp. 6, Italy.

[33] R. Chassaing, Digital Signal Processing and Applications with the TMS320C6713 and TMS320C6416 DSK, 2nd ed. New Jersey: John Wiley \& Sons, Inc, 2008, pp. 557-560.

[34] N. Mohan, T. Undeland, W. Robbins, Power electronics: converters, applications, and design, John Wiley \& Sons, 1995.

[35] M. Liserre, F. Blaabjerg, R. Teodorescu, Z. Chen, Power converters and control of renewable energy systems, ICPE 2004, Busan, Korea, Invited paper.

[36] J. Liang, T.C. Green, G. Weiss, Q. Zhong, Hybrid control of multiple inverters in an island-mode distribution system, PESC '03. IEEE 34th annual conference on power electronics specialist, 2003, vol. 1, pp.61-66, June 2003.

[37] T. Esram, P.L. Chapman, Comparison of Photovoltaic Array Maximum Power Point Tracking Techniques, Energy Conversion, IEEE Transactions on , vol.22, no.2, pp.439-449, June 2007.

[38] N. Femia,, G. Petrone, G. Spagnuolo, M. Vitelli, Optimization of perturb and observe maximum power point tracking method, Power Electronics, IEEE Transactions on , vol.20, no.4, pp. 963- 973, July 2005

[39] M. P. Kazmierkowski, R. Krishnan, F. Blaabjerg, Control in power electronics, Academic Press, London, 2002.

[40] IEEE recommended practice for grid interface of photovoltaic (PV) systems, IEEE Std. 929, 2000.

[41] M. Ciobotaru, R. Teodorescu, F. Blaabjerg, A new singlephase PLL structure based on second order generalized integrator, in Record of IEEE PESC 2006, Jeju, Korea, p. 1511-1516.

[42] M. Liserre, A. Timbus, R. Teodorescu, F. Blaabjerg, Synchronization methods for three phase distributed power generation systems. An overview and evaluation, PESC 2005, Recife, Brasile.

[43] R. Beck, A.G. Dempster, I. Kale, Finite-precision Goertzel filters used for signal tone detection, Circuits and Systems II: Analog and Digital Signal Processing, IEEE Transactions on, vol.48, no.7, pp.691-700, Jul 2001.

[44] T. Zhao, D.S. Zinger, Induction motor speed detection by applying Goertzel's algorithm to current harmonics, Applied Power Electronics Conference and Exposition, 2000. APEC 2000. Fifteenth Annual IEEE, vol.1, pp.140-143 vol.1, 2000.

[45] J. Kim; S.W. Lee; S.R. Lee; T.W. Lee; C.Y. Won, Power quality control using the Goertzel algorithm for grid-connected system, Telecommunications Energy Conference, 2009. INTELEC 2009. 31st International, pp.1-3, 18-22 Oct. 2009.

[46] M. Liserre; R. Teodorescu; F. Blaabjerg, Stability of photovoltaic and wind turbine grid-connected inverters for a large set of grid impedance values, Power Electronics, IEEE Transactions on , vol.21, no.1, pp. 263- 272, Jan. 2006

[47] IEEE recommended practice for grid interface of photovoltaic (PV) systems, IEEE Std. 929, 2000.

[48] PSIM 7.0 User’s Guide. 2006, Powersim Inc., March 2006.

[49] S. Buso, P. Mattavelli, Digital Control in Power Electronics, Morgan \& Claypool, 2006, pp. 21-23.

[50] F. De Mango, M. Liserre, A.D. Aquila, Overview of Anti-Islanding Algorithms for PV Systems. Part II: ActiveMethods, Power Electronics and Motion Control Conference, 2006. EPE-PEMC 2006. 12th International , vol., no., pp.1884-1889, Aug. 30 2006-Sept. 1 2006 